\title{
Fully mechanised installation of high-tensile chain-link mesh for surface support in tunnels
}

\author{
R. Coates ROCK (Australia) Engineering Pty Ltd, Australia \\ S. Brown ROCK (Australia) Engineering Pty Ltd, Australia \\ R. Bucher Geobrugg Australia Pty Ltd, Australia
}

A. Roth Geobrugg AG Protection Systems, Switzerland

\begin{abstract}
Seismicity and related rockburst damage poses a common hazard in deep underground mining operations all over the world. Most standard ground support schemes are not able, or only have a limited capacity to cope with dynamic loading caused by rockbursts. High-tensile steel wire mesh has proven its performance and suitability for the application as rockburst support or support for high-deformable ground during static and dynamic tests at the Western Australian School of Mines (WASM) in Kalgoorlie, Australia. Due to the hightensile wire strength and ability for high deformation of the high-tensile mesh, this ground support system can be used in high stressed environments.

An automated roll mesh handler was developed and successfully tested in Australia for the application of high-tensile chain-link mesh in underground support. The handler is compatible with all standard multiboom jumbo drilling equipment. The mesh handler comprises a cassette system holding the mesh roll mounted on one of the booms and the drilling/bolting element is mounted on the other boom. This allows the application and pinning of the high-tensile mesh simultaneously.

The innovation reduces manual handling and personnel exposure in the installation process, reduces support cycle time (initial trials suggest a quicker installation time over current sheet mesh methods), improves the quality as the high-tensile mesh conforms more closely to the rock surface. This reduces unravelling of material in the voids and bagging of the mesh. There is no need for personnel to enter unsupported ground as the jumbo and mesh handler is used to pick up the high-tensile mesh roll and transport it to the unsupported area. Both the high-tensile chain-link mesh and its fully mechanised installation significantly increase the safety of mining personnel and rapidity of mining development.
\end{abstract}

\section{Introduction}

The primary ground support in underground mining operations without rockburst hazard mainly consists of weld mesh panels and friction bolts. In going deeper and deeper, mines experience increasing seismicity and associated rockburst damage. In order to cope with this hazard, specially designed rockbolts with better energy absorption and elongation capacity were introduced. These bolts also suit highly deformable ground, however, between the bolts surface support is required and the only strategy at the moment is to use thick fibre or weld mesh reinforced shotcrete. This tends to be expensive and slow to install. It is very stiff and reacts poorly to impacts.

Weld mesh panels are easy to handle. They are strong and stiff enough to prevent small rockfalls and subsequent unravelling of the tunnel roofs, but they do not have the ability to absorb larger dynamic impacts. The welded connections are brittle and normally fail first, followed by the strands when the loads get higher.

High-tensile steel wire mesh showed good performance in rockfall and rockburst testing. Due to its strength and flexibility the mesh was able to absorb the kinetic energy thereby slowing down the impacting rock masses. The high strength of the mesh is necessary to transfer the resulting forces of a rockburst impact to the anchors and to avoid puncturing of the mesh by the impacting rock masses.

In order to use it as a standard product for ground support, a safe and automated installation method had to be developed. The aim of this system is to provide mine operators with an efficient and effective way to 
install rolled high-tensile chain-link mesh. Furthermore, it was considered desirable that the mesh handler should be capable of being retro-fitted on all commonly used underground drilling equipment, thus obviating the purchase of new machines.

\section{$2 \quad$ High-tensile chain-link mesh for ground support}

The Tecco chain-link mesh is made of high-tensile steel wire with a diameter of four $\mathrm{mm}$ and a tensile strength of $1770 \mathrm{MPa}$. This high-tensile wire has an excellent shear and impact resistance. The mesh is diamond shaped and along the edges, the wires are bent over and double twisted in such a way that this connection is as strong as the mesh itself (Figure 1a). The mesh is produced in rolls (Figure 1b) and can be manufactured in widths up to five metres and in tailor-made lengths. Due to the use of high-tensile wire, the mesh is very light in relation to its strength. For corrosion protection the wires are coated with a special aluminium-zinc coating which has a higher corrosion resistance than standard galvanising.

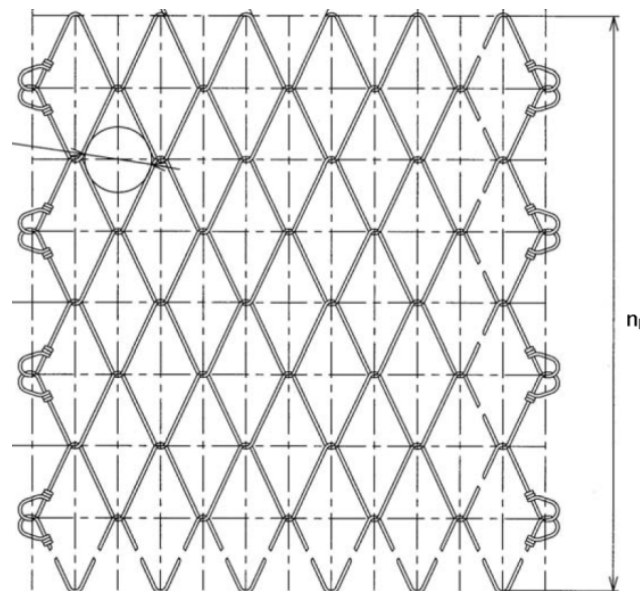

(a)

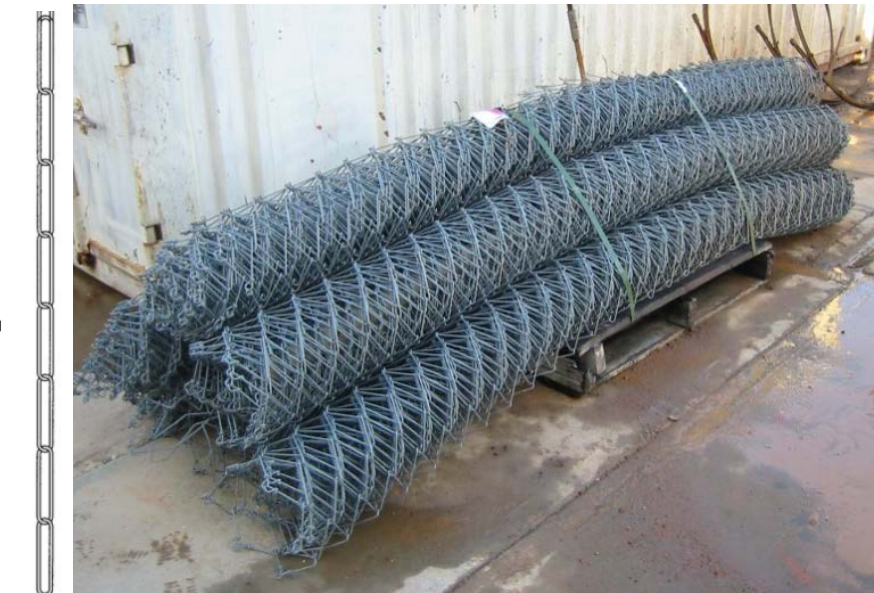

(b)

Figure 1 (a) Geometry of the Tecco mesh; and (b) the delivery of the mesh in rolls

The mesh geometry was designed in such a way that it has a very high breaking load as well as low deflection characteristics to avoid inadmissible deflection rates and unravelling of the rock after a rockburst impact. The resistance properties of the mesh were determined in several laboratory testing series by Torres (2002) at the University of Cantabria in Santander, Spain. The properties of the mesh G80/4 with a wire diameter of four mm are summarised in Table 1.

Table 1 Properties of the high-tensile Tecco mesh G80/4

\begin{tabular}{ll}
\hline Material & Tecco G80/4 \\
\hline Mesh opening & $102 \times 177 \mathrm{~mm}$ \\
Wire diameter & $4 \mathrm{~mm}$ \\
Wire strength & $1770 \mathrm{MPa}$ \\
Breaking load of single wire & $22 \mathrm{kN}$ \\
Tensile strength & $190 \mathrm{kN} / \mathrm{m}$ \\
Weight & $2.6 \mathrm{~kg} / \mathrm{m}^{2}$ \\
\hline
\end{tabular}

\section{$3 \quad$ Testing of high-tensile chain-link mesh}

In order to determine the mechanical properties of the high-tensile mesh, it was extensively tested both in static and dynamic modes at WASM. For the dimensioning of the support scheme consisting of mesh and bolts, a numerical model was developed, calibrated and verified by the Swiss Federal Research Institute (WSL) with a finite element code. 


\subsection{Static testing}

The static response of high-tensile chain-link mesh was determined by test work in the WASM laboratories. Figure 2 shows the response of three samples of the high-tensile mesh Tecco G80/4 where a $1.3 \times 1.3 \mathrm{~m}$ panel was loaded with a 300 x $300 \mathrm{~mm}$ steel plate. The test setup is described by Morton et al. (2007). The high-tensile mesh was able to bear loads up to $110 \mathrm{kN}$ before it failed at the edge of the loading plate. Weld mesh in comparison failed with approximately $40 \mathrm{kN}$, and mild steel chain-link failed with less than $20 \mathrm{kN}$ using the same test setup. All mesh types require some displacement at the beginning to be activated and loaded. The stiffness of high-tensile chain-link and weld mesh was found to be similar and more dependent on the boundary conditions than the type of mesh.

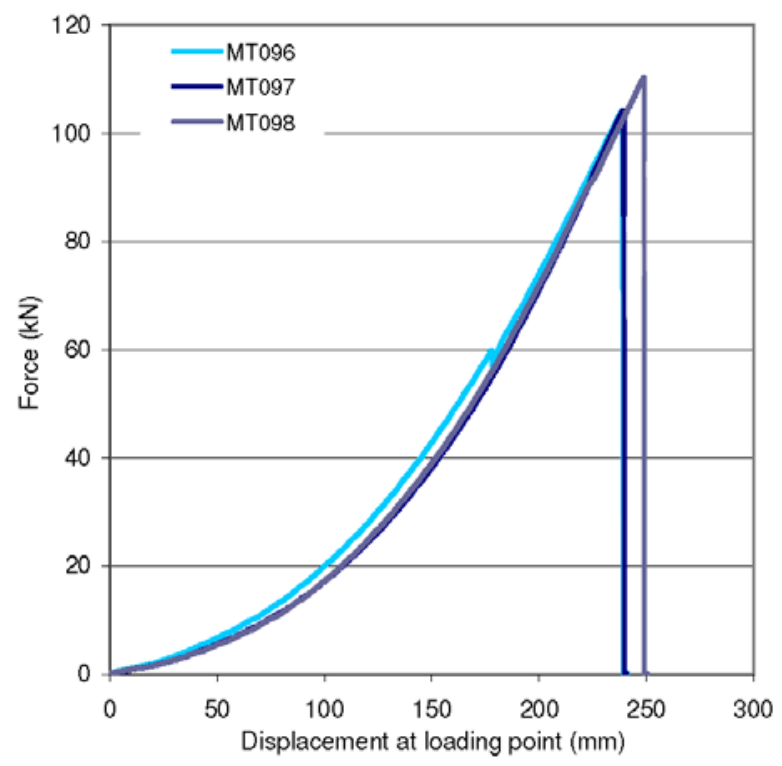

Figure 2 Force displacement responses of three samples of the high-tensile chain-link mesh Tecco G80/4 (Test No. MT096-098 by Morton, 2008)

It was also found that the high-tensile chain-link mesh can sustain an increase in load even after a wire has failed. It also does not unravel once a wire has failed (Roth et al., 2004). Ruegger (1999) tested the hightensile mesh in a way quite similar to an application in mining (with four bolts and plates) and stated that the rupture is generally starting at the crossing points but is not sheared over the edge of the plates due to the higher steel quality of the mesh compared to the mild steel plates.

\subsection{Dynamic testing}

By using the momentum transfer method (Player et al., 2004; Thompson et al., 2004) the high-tensile chainlink mesh was tested at the dynamic testing facility of WASM (Player et al., 2008). The mesh panel is installed in a loading frame in which a steel weight can be dropped onto the mesh from different heights. Rebound off the loading frame is stopped by buffers while the loading mass impacts the mesh sample without being separated from it. The whole dynamic test is instrumented with high-speed video cameras, load cells and accelerometers.

Figure 3 shows a sequence from the high-speed video camera where a mass of $1000 \mathrm{~kg}$ (bag with mill steel balls) hits the high-tensile chain-link mesh. The mesh deforms according to the applied load and transfers the forces to the boundary. The boundary conditions are set unmoveable in order to have comparable and repeatable results. 


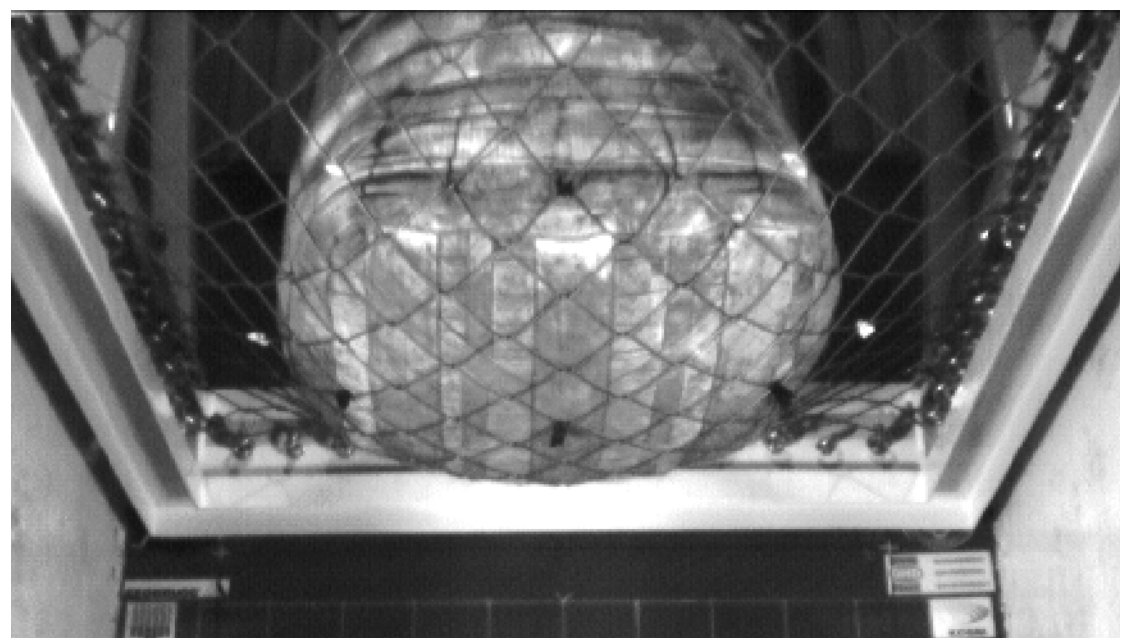

Figure 3 Dynamic impact of a 1000 kg mass into the high-tensile chain-link (Player, 2007)

It was established that the high-tensile chain-link mesh is able to absorb energies of up to $10-12 \mathrm{~kJ}$ in such a configuration. This is equal to stopping a rockburst mass of $1000 \mathrm{~kg}$ which was previously accelerated to $4.5-5 \mathrm{~m} / \mathrm{s}$. This value represents the value of the energy absorption of the mesh only and does not include any absorption by the rock mass itself or the yielding bolts. Welded wire mesh (wire diameter $5.6 \mathrm{~mm}$ and $100 \mathrm{~mm}$ wire spacing) showed energy absorption capacities in the area of 1-2 kJ in the same test setup.

\subsection{Numerical model}

For the numerical model, we sought an algorithm which was able to handle large deformations and also dynamic impacts. For that purpose, a code was chosen which was based on a discrete finite element method (FEM) and a model of rope and truss elements. In order to simulate dynamic impacts, Newton's second law is applied together with the material properties of the single components ('time-stepping'). The software FARO ('falling rock') was developed by the Swiss Federal Institute of Technology (ETH) and the WSL (Volkwein et al., 2002).

Figure 4a shows the static mesh tests executed by Roth et al. (2004) with the mesh and a bolt pattern of $1 \mathrm{x} 1 \mathrm{~m}$ where the mesh was loaded with a steel frame. These tests were used to calibrate the numerical model as shown in Figure 4b. With the calibrated FEM model it becomes possible to perform dynamic simulations and predict forces, failure modes and deformations of the different components.

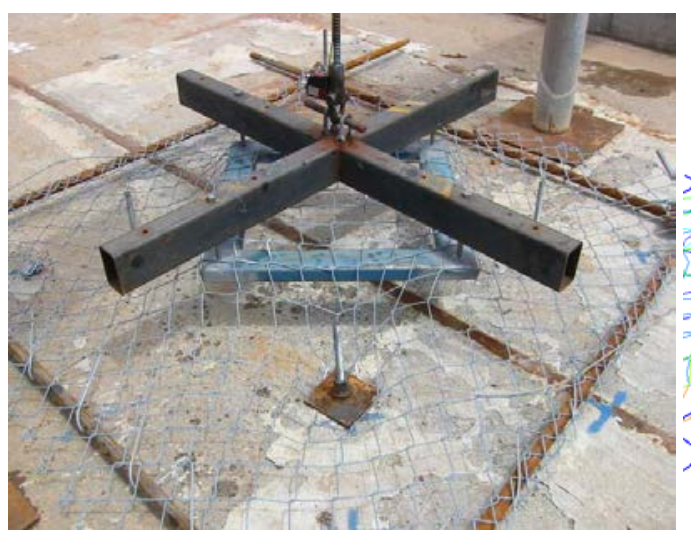

(a)

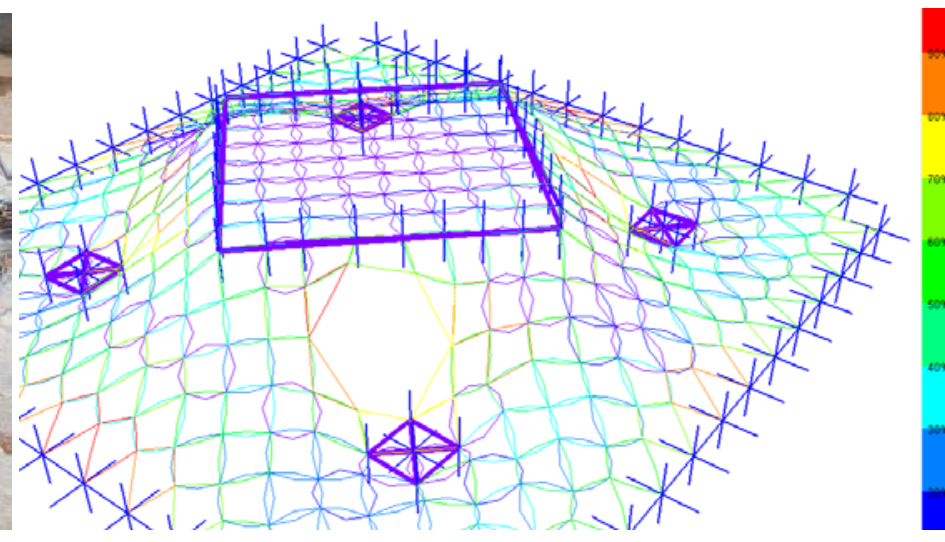

(b)

Figure 4 (a) Static mesh tests; (b) the calibration of the numerical model

With the numerical model of a ground support system with high-tensile steel wire mesh, it is possible to simulate the dynamic response of any setup and loading. Input parameters can be adjusted to specific project parameters and the bolt pattern and maximum deflections can be determined. This makes ground support 
schemes for dynamic loading designable. It is very important to have a support system where the components fit together. With the calibrated numerical model it is possible to connect different bolt types with the high-tensile steel wire mesh and determine if they work together under given conditions. Since there is always a load concentration on the bolt plates, higher loads could be achieved by using special plates which are able to grab more wires.

\section{$4 \quad$ Installation of high-tensile chain-link mesh in tunnels}

The difference between the installation of welded wire mesh and the installation of chain-link mesh is the stiffness of the products. The welded wire mesh is relatively stiff and is delivered and applied in sheets. The chain-link mesh is only stiff in one direction but rollable in the other. Therefore it is delivered in rolls (Figure $1 \mathrm{~b}$ ) and has to be installed in a different way to welded wire mesh.

The manual installation of chain-link mesh is mainly done with scissor lifts or baskets attached to tool carriers, but this is quite labour intensive. Therefore a new way was conceived, comprising a mesh handler to unroll the mesh and hold it onto the surface of the tunnel while it was pinned to the rock with the second jumbo boom. The main objectives were the rapidity and safety of the installation in order to comply with the targets of modern mining both in terms of safety and economics.

\subsection{Manual installation of chain-link mesh}

For the installation of chain-link mesh, the mesh has to be unrolled around the tunnel profile and pinned to anchors. During manual installation, the anchors are often installed prior to the mesh which is attached to the anchors later. For that purpose scissor lifts or baskets on tool carriers are used (Figure 5).

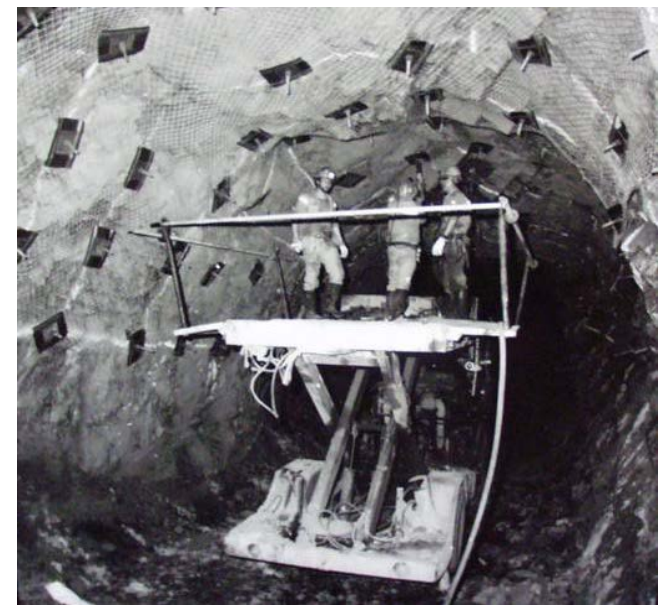

(a)

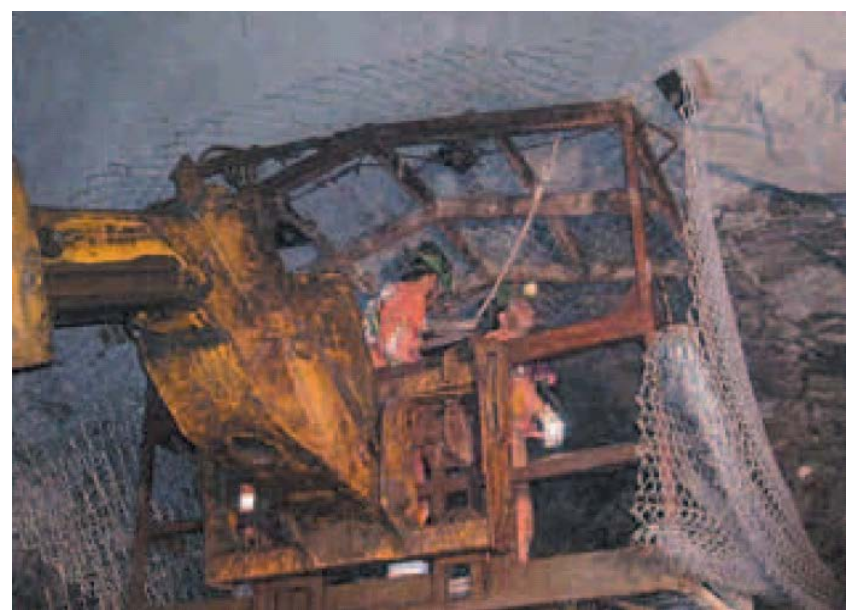

(b)

Figure 5 (a) Manual installation of mesh with scissor lift (Villaescusa, pers.comm., 2003); (b) installation basket on tool carrier

These methods have the disadvantage that they are quite slow and labour intensive. It is also hard to get the right tension on the chain-link mesh which is important to have a maintenance friendly system. Furthermore, the workers have to install the mesh under non supported ground which does not comply with state-of-the-art safety standards.

\subsection{Fully mechanised installation with mesh handler}

An automated roll mesh handler for the application of high-tensile chain-link mesh was developed and successfully tested in Australia for the installation of support in underground workings. The handler is compatible with all standard multi-boom jumbo drilling equipment, applying mesh from a cassette system. The mesh handler with the mesh roll is mounted on one boom and the drill/bolter mounted on the other boom of the jumbo. The application of the high-tensile mesh and installation of split-sets or bolts happens at the same time. 
The mesh handler (Figure 6) can grab the rolled mesh and can unroll it along the tunnel walls and back in both directions. Meanwhile the second boom of the jumbo can pin the mesh to the rock. This is done step by step to make sure that the mesh is as tight as possible. In order to tighten the mesh between the anchors, the mesh handler is fitted with a system to tighten (and also loosen) the mesh by 'positively' revolving the roll in both directions.

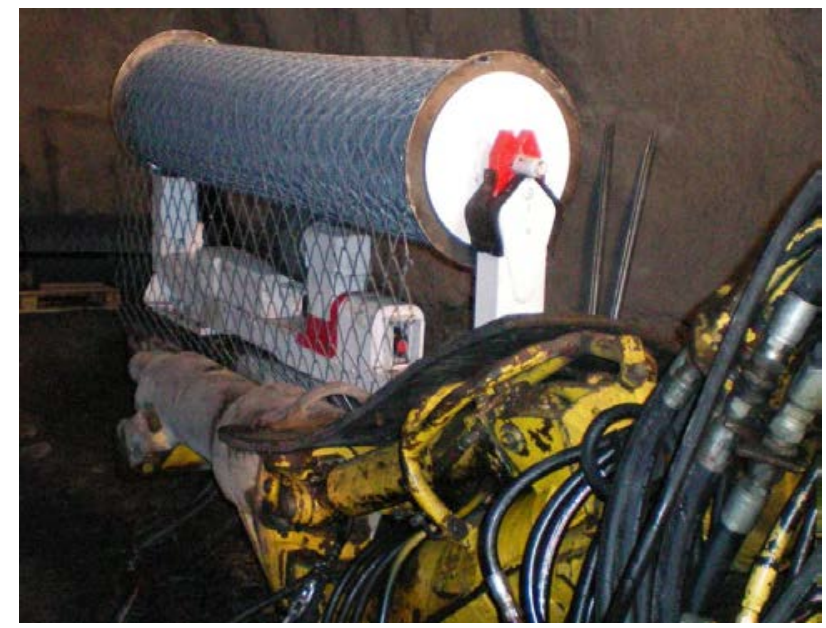

Figure 6 Mesh handler mounted on jumbo boom

The system reduces manual handling and personnel exposure in the installation process, it reduces support cycle time, improves quality with high-tensile mesh contouring more closely to the rock surface - reducing unravelling/bagging of material in voids. No personnel are exposed to unsupported ground, due to the ability of the jumbo to pick-up the Tecco mesh roll cassette with the manipulator arm on its way to the unsupported area.

\subsection{In situ installation trial}

In order to test and commission the mesh handler, an in situ trial was carried out with a two metre wide roll of high-tensile chain-link mesh in an underground mine in Western Australia. The mesh handler was fitted on a twin-boom Sandvik jumbo which is owned and operated by the mining company. The feed was removed from one of the booms and the mesh handler was installed onto it. The existing drilling hydraulic circuit was used to control the functions of the mesh handler (Figure 7).
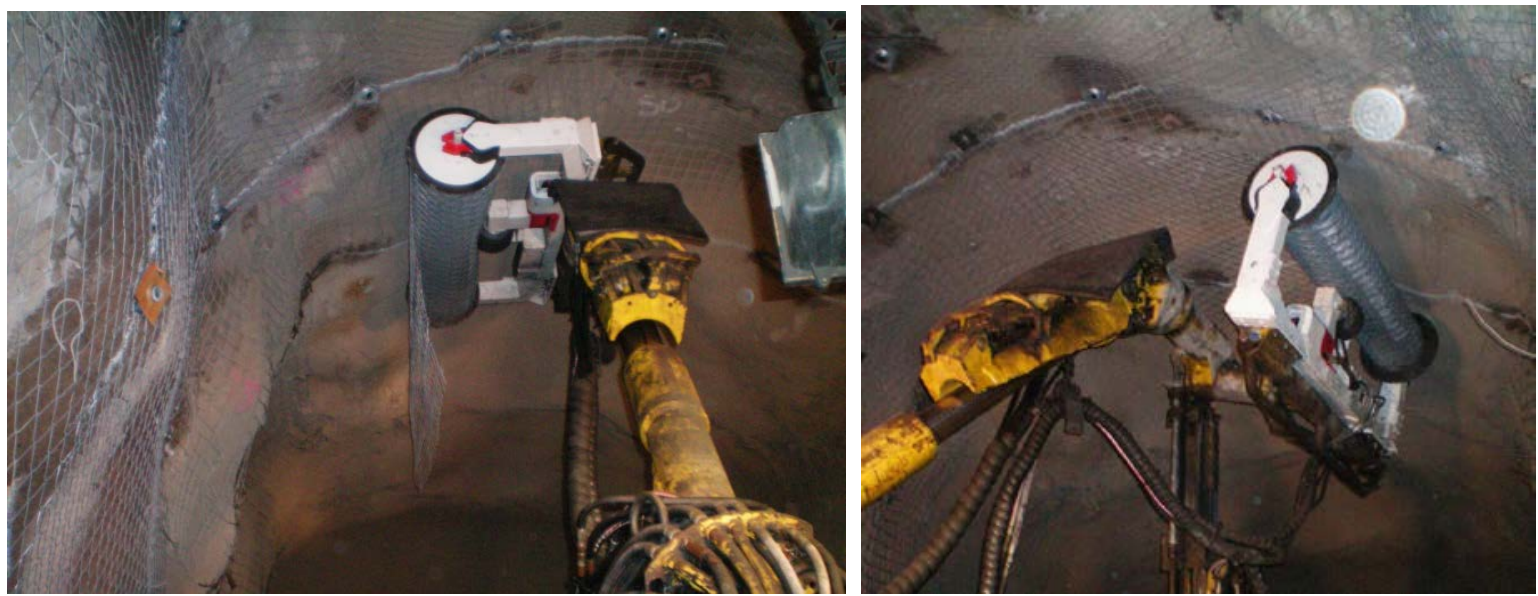

Figure 7 Installation trials in a Western Australian underground mine

There were some concerns that the mesh would 'balloon' away from the wall and allow scat and larger rocks to accumulate in these balloons. This was not the case, once the mesh had been anchored to the walls and 
backs, it was noted that the mesh had actually followed the contours of the rock and pulled tightly into the wall giving a smooth and even texture in the area.

The installation trial showed that it was possible to install the high-tensile chain-link in less time than standard weld mesh even though the operator was doing it for the first time. With an optimisation of the installation process, it will be possible to have an even more rapid meshing cycle without compromising the safety of the operation.

\section{Conclusions}

After successfully testing the high-tensile chain-link mesh in both static and dynamic tests, it could be proven that this kind of mesh is suitable for ground support in areas prone to rockbursts and also highdeformable ground. In contrast to shotcrete, or fibrecrete, the rock remains visible for inspection by geotechnical personnel. For a rockburst ground support scheme suitable bolts and plates have to be chosen to be combined with the high-tensile mesh. The system can be dimensioned with the calibrated numerical model. With the described method of installation, this new type of mesh can be installed easily and even more quickly than commonly used ground support methods.

With mechanised application, the high-tensile chain-link mesh reduces application time. It allows optimising work cycles and optimising or extending bolt spacing. High-tensile mesh with a smaller diameter could be used as reinforcement of shotcrete.

It can be concluded that both the high-tensile chain-link mesh and its fully mechanised installation can significantly increase the safety of mining personnel, the quality of the installed ground support and the rapidity of mining development.

\section{Acknowledgements}

The authors would like to thank Ernesto Villaescusa, John Player, Ellen Morton, Chris Windsor and Alan Thompson from the Western Australian School of Mines (WASM) for their greatly appreciated contribution to this project.

\section{References}

Morton, E., Thompson, A., Villaescusa, E. and Roth, A. (2007) Testing and analysis of steel wire mesh for mining applications of rock surface support, ISRM Symposium, Lisbon, Portugal.

Morton, E. (2008) Test report on static testing of Tecco mesh G80/4, Western Australian School of Mines (WASM), pp. 1-15.

Player, J., Villaescusa, E. and Thompson, A. (2004) Dynamic testing of rock reinforcement using the momentum transfer concept, Proceedings of the Fifth International Symposium on Ground Support in Mining and Underground Construction, E. Villaescusa and Y. Potvin (eds), September 2004, Perth, Australia, A.A. Balkema, The Netherlands, pp. 327-339.

Player, J., Morton, E., Thompson, A. and Villaescusa, E. (2008) Static and dynamic testing of steel wire mesh for mining applications of rock surface support, Proceedings of the Sixth International Symposium on Ground Support in Mining and Civil Engineering Construction, Cape Town, South Africa, The South African Institute of Mining and Metallurgy, pp. 693-706.

Player, J. (2007) Test report on dynamic testing of Tecco mesh, Western Australian School of Mines (WASM), pp. 1-24.

Roth, A., Windsor, C., Coxon, J. and deVries, R. (2004) Performance assessment of high-tensile steel wire mesh for ground support under seismic conditions, Proceedings of the Fifth International Symposium on Ground Support in Mining and Underground Construction, E. Villaescusa and Y. Potvin (eds), September 2004, Perth, Australia, A.A. Balkema, The Netherlands, pp. 589-594.

Ruegger, R. (1999) Penetration tests of the Tecco mesh with four plates, Test Report, Ruegger Systems, St. Gallen, Switzerland, pp. 1-8.

Thompson, A., Player, J. and Villaescusa, E. (2004) Simulation and analysis of dynamically loaded reinforcement systems, Proceedings of the Fifth International Symposium on Ground Support in Mining and Underground Construction, E. Villaescusa and Y. Potvin (eds), September 2004, Perth, Australia, A.A. Balkema, The Netherlands, pp. 341-355.

Torres, J.A. (2002) Tecco mesh, evaluation Tecco G80, technical report, University of Cantabria, Santander, Spain, pp. 1-27. 
Volkwein, A., Anderheggen, E. and Grassl, H. (2002) Numerical simulation of highly flexible rockfall protection systems, Proceedings of the Fifth World Congress on Computational Mechanics, Vienna, Austria, pp. 224-230. 